Article

\title{
Strategies and Policies for the Bioeconomy and Bio-Based Economy: An Analysis of Official National Approaches
}

\section{Louise Staffas $^{1, *}$, Mathias Gustavsson ${ }^{2}$ and Kes McCormick ${ }^{3}$}

1 IVL Swedish Environmental Research Institute, Box 21060, Stockholm SE-10031, Sweden

2 IVL Swedish Environmental Research Institute, Box 53021, Göteborg SE-40014, Sweden; E-Mail: mathias.gustavsson@ivl.se

3 International Institute for Industrial Environmental Economics (IIIEE), Lund University, Box 196, Lund SE-22100, Sweden; E-Mail: kes.mccormick@iiiee.lu.se

* Author to whom correspondence should be addressed; E-Mail: louise.staffas@ivl.se; Tel.: +46-8-5985-6448; Fax: +46-8-5985-6390.

Received: 2 May 2013; in revised form: 3 June 2013 / Accepted: 8 June 2013 /

Published: 20 June 2013

\begin{abstract}
The onset of formulating strategies and policies regarding the bioeconomy can be, at least partly, attributed to the publication of the policy agenda on the bioeconomy by the Organisation for Economic Cooperation and Development in 2009. The aim of this study is to analyze selected national strategies and policies regarding the development of a bioeconomy and to clarify similarities and differences between them. The article presents a comparative overview of the strategies and policies for developing a bioeconomy in the EU, USA, Canada, Sweden, Finland, Germany and Australia. The documents analyzed are in most cases national strategies or policies. The structures and aims of these documents vary and the analysis is further complicated by the terms "bioeconomy" and "bio-based economy" having as yet no clear definition, a point which is discussed in some depth in this article. In the documents analyzed, strategies and policies on how to promote the bioeconomy are often presented based on the prerequisites of the country in focus; the need for increased research, development and demonstrations in the area is thus particularly stressed. The main emphasis is often to enhance the economy of a nation and provide new employment and business possibilities, whereas the aspects of sustainability and resource availability are addressed only to a limited extent in many of the documents.
\end{abstract}

Keywords: bioeconomy; bio-based economy; strategy; policy 


\section{Introduction}

The transition from a fossil fuel-dependent development paradigm towards a development path that takes advantage of bio-based resources and new innovations within biochemistry and the life sciences is prompting the formulation of new strategies and policies. With increased research and innovations on bio-based energy forms, chemicals and materials, the use of the terms bioeconomy (BE) and bio-based economy (BBE) has evolved. Interestingly, there is a slight difference between the meanings of these two terms and also in how they are used, although this difference is neither obvious nor outspoken, which is further explained in this article. The use of the two terms in this article will, as often as possible, be used stringently, but when mentioned as a general concept, the term bioeconomy also comprises the bio-based economy.

Until now, many countries have published separate strategies and policies related to biotechnology and bio-based products and industries, but more and more countries are developing strategies that collect all these separate topics under the conceptual umbrella of the BE. A shift towards a larger and more advanced bioeconomy will imply effects on many aspects of the economy, society in general, and the environment. With a strategy for a BE, a nation declares its intentions in a more coordinated way, sometimes including the aspects of protecting biodiversity, food quality and quantity, preservation of rare biotopes, and climate change mitigation. The fact that some of the world's largest countries and economies have adopted national strategies and visions for such a bioeconomy is relevant for all actors in research and economic arenas (see for example [1-3]).

The onset of publications of national bioeconomy strategies and policies can be, at least partly, attributed to the publication of the Organisation for Economic Cooperation and Development (OECD) document “The Bioeconomy to 2030: Designing a Policy Agenda” [1], which states that progress in biological sciences can now offer solutions for many health and resource-related issues that the world is facing. These technologies can provide a motor for increased sustainability in economies but defining a policy agenda is required to implement the research findings and innovations that are the basis of a BE. The OECD strongly suggests that both the public and the private sectors must take active roles in designing such an agenda in order to maximize the full potential of the bioeconomy.

The aim of this article is to give a comparative analysis of a sample of national strategies and policies on the BE and BBE. The countries and regions selected are the EU, USA, Canada, Germany, Finland, Sweden and Australia. However, in order to set a frame for these strategies, the overview starts with a description of the OECD agenda on the bioeconomy. The selected countries are major actors for developing a $\mathrm{BE}$ and/or they are relatively rich in bio-based resources or potentials. The USA, Canada, Finland and Sweden have large forest areas, which is an important factor for developing a BE, and they also have research and innovation in the field of bio-refining and bio-based industries. Germany has recently declared its intention of shutting down all its nuclear power plants, which provides a major driver for renewable energy and developing the bioeconomy. Australia faces the challenge of water scarcity, climate impacts on its fragile environment, and increasing renewable energy. Both Germany and Australia have significant potentials for the bioeconomy. The EU is a key player in the BBE field having declared a strong emphasis on the "knowledge-based bio-economy" or KBBE, encompassing research, development, and demonstration and other types of projects in fields such as agriculture, bioenergy, new materials, and biorefineries. 


\section{Methodology}

This article is a study of how national (and regional) strategies and policies around the BBE and BE are formulated. The analysis covers only governmental, official documents or documents that are treated, in the country itself and/or internationally, as primary documents. Examples of non-governmental documents that are referred to as national strategies or policies are those from Canada and Australia. There are many non-governmental strategies and agendas published, but since these are not within the scope of this project, they are not included in the comparison. The methods used in this research include a systematic search for, and identification of, relevant documents and background information and an analysis based on a set of parameters. This overview is presented in an evaluation matrix, shown in Table 1. Subsequently, descriptions of each document are presented, thus providing more detailed insights. Finally, the focus and approaches of the documents are compared and discussed and some conclusions are drawn.

The countries selected in this study are the USA, Canada, Germany, Sweden, Australia and Finland. In addition, the EU has been included, as well as the bioeconomy report from the OECD. The inclusion of the OECD document [1] was motivated by frequent referral to it in the policies and strategies of the aforementioned countries. Other countries relevant to the global bioeconomy but not included in this study are, for example, Russia, which launched an innovation strategy in 2010 entitled “Innovative Russia 2020" [4]; China is pursuing a strong position in the bioeconomy with a special focus on biochemistry and life sciences [5,6]; Malaysia has a vision for the creation of a bioeconomy [7], as well as a "National Biomass Strategy to 2020" [8]; and Brazil issued in 2007 a decree including an annex detailing the development of its bioeconomy [9]. Russia, China, Malaysia and Brazil are not included in this study as their official national documents on the bioeconomy are not well developed but, clearly, these countries are globally important and deserve further attention. 
Table 1. Overview of BE and BBE strategies and policies.

\begin{tabular}{|c|c|c|c|c|c|c|c|c|}
\hline $\begin{array}{l}\text { Country } \\
\text { or } \\
\text { region }\end{array}$ & $\begin{array}{c}\text { Publication } \\
\text { year }\end{array}$ & $\begin{array}{l}\text { Document } \\
\text { title }\end{array}$ & Source & $\begin{array}{c}\text { Definition: } \\
\text { Bio-based } \\
\text { Economy (BBE) or } \\
\text { Bioeconomy (BE) }\end{array}$ & $\begin{array}{l}\text { Focus: Technical } \\
\text { and/or political }\end{array}$ & $\begin{array}{c}\text { Measureable } \\
\text { targets }\end{array}$ & $\begin{array}{l}\text { Priority } \\
\text { areas }\end{array}$ & References \\
\hline OECD & 2009 & $\begin{array}{l}\text { The Bioeconomy to 2030: } \\
\text { Designing a Policy Agenda }\end{array}$ & $\begin{array}{c}\text { Organisation for } \\
\text { Economic Cooperation } \\
\text { and Development } \\
\text { (OECD) }\end{array}$ & $\mathrm{BE}$ & $\mathrm{T}$ & No & $\begin{array}{l}\text { Biotechnology, } \\
\text { agriculture, health } \\
\text { and industry }\end{array}$ & {$[1,10]$} \\
\hline EU & 2012 & $\begin{array}{l}\text { Innovating for Sustainable } \\
\text { Growth: A Bioeconomy for Europe }\end{array}$ & $\begin{array}{l}\text { European Commission } \\
\text { (EC) }\end{array}$ & $\mathrm{BBE}$ & $\begin{array}{l}\mathrm{P}, \mathrm{T} \text { in a working } \\
\text { document } \\
\text { accompanying the } \\
\text { strategy }\end{array}$ & $\begin{array}{l}\text { Economic } \\
\text { targets and } \\
\text { scenarios }\end{array}$ & $\begin{array}{c}\text { Food, resources, } \\
\text { innovation and skills }\end{array}$ & {$[3,11]$} \\
\hline USA & 2012 & National Bioeconomy Blueprint & $\begin{array}{l}\text { White House } \\
\text { Administration }\end{array}$ & $\mathrm{BE}$ & $\mathrm{P}$ & $\begin{array}{c}\text { Yes, } \\
\text { qualitative }\end{array}$ & Biotechnology & {$[2]$} \\
\hline Canada & 2009 & $\begin{array}{l}\text { The Canadian Blueprint: } \\
\text { Beyond Moose and Mountains }\end{array}$ & BioteCanada & $\mathrm{BE}$ & $\mathrm{P}$ & $\begin{array}{c}\text { Yes, } \\
\text { qualitative }\end{array}$ & Biotechnology & {$[12]$} \\
\hline Germany & 2011 & $\begin{array}{c}\text { National Research Strategy: Our } \\
\text { Route Towards a Biobased } \\
\text { Economy }\end{array}$ & $\begin{array}{c}\text { Federal Ministry of } \\
\text { Education and Research }\end{array}$ & $\mathrm{BBE}$ & $\mathrm{T}$ & $\begin{array}{c}\text { Yes, } \\
\text { quantitative }\end{array}$ & $\begin{array}{l}\text { Agriculture, health, } \\
\text { food and energy }\end{array}$ & {$[13,14]$} \\
\hline Finland & 2011 & $\begin{array}{l}\text { Distributed Bio-Based Economy: } \\
\text { Driving Sustainable Growth }\end{array}$ & $\begin{array}{l}\text { Finnish Innovation } \\
\text { Fund (SITRA) }\end{array}$ & BBE & $\mathrm{P}$ & $\begin{array}{c}\text { Yes, } \\
\text { qualitative }\end{array}$ & $\begin{array}{l}\text { Efficient resource } \\
\text { use and biomass } \\
\text { refining }\end{array}$ & {$[15]$} \\
\hline Sweden & 2012 & $\begin{array}{l}\text { Swedish Research and Innovation } \\
\text { Strategy for a Bio-based Economy }\end{array}$ & $\begin{array}{l}\text { Swedish Research } \\
\text { Council for the } \\
\text { Environment, } \\
\text { Agricultural Sciences } \\
\text { and Spatial Planning } \\
\text { (FORMAS) }\end{array}$ & BBE & $\mathrm{T}$ & No & $\begin{array}{c}\text { Efficient resource } \\
\text { use and research gaps }\end{array}$ & {$[16]$} \\
\hline Australia & 2008 & $\begin{array}{l}\text { Biotechnology and } \\
\text { Australian Agriculture }\end{array}$ & ACIL Tasman & $\mathrm{BE}$ & $\mathrm{T}$, explanatory & No & $\begin{array}{l}\text { Agriculture and } \\
\text { biotechnology }\end{array}$ & {$[17]$} \\
\hline
\end{tabular}




\section{Background}

It is important to put the transition to a bioeconomy in context. Kircher $[18,19]$ has compared the amounts of fossil-derived carbon used today with the available amount through photosynthesis. There are 3.3 bn ton/year in the total amounts of oil produced (of which 92\% is used for energy purposes and 8\% for providing chemicals) and 7.2 bn ton/year of coal carbon (of which almost all is for energy purposes). This can be compared to 105 bn ton/year carbon through photosynthesis, of which 7 bn ton/year are produced by agriculture and used for production of food, feed and fiber (and some energy and chemicals) and it is therefore not available for replacing oil and other fossil resources. Pan et al. [20] have estimated the net carbon sequestration in forests to $1.1 \pm 0.8$ bn tons/year. Agriculture and forestry alone will therefore not be able to replace the fossil carbon used today.

There are, however, other forms of biomass, such as micro and macro algae. The use of algae is so far not exploited to its full potential, but there are suggestions that algae will constitute a significant feedstock for several chemical substances and also energy [21,22]. In addition to biomass, there are also other renewable energy sources that can contribute to a low-carbon energy system, but even with these included, margins are small and, in addition to replacing as much fossil carbon as possible with bio-based resources, it is vital to use these resources in an efficient way. Forecasts on whether these energy forms will be able to contribute significantly to a fossil-free economy or not is, however, not within the scope of this study, but it is clear that replacing fossil resources for energy, chemicals and materials with renewable and bio-based feedstocks is a major challenge.

\section{Definitions}

The terms BBE and BE have, during recent years, been increasingly used and discussed (see Figure 1). In fact, the number of scientific articles including "bio-based economy", "biobased economy”, "bioeconomy” or "bio-economy” in titles, abstracts or keywords has markedly increased. The number of citations of these words in Scopus shows that in 2005 the number of articles started to rise rapidly [23]. Even though the BBE and BE concepts relate to how bioresources are utilized in the economy, there are some notable differences in the way the terms are used. In some cases, the terms are used in a stringent form, but many of the texts studied and referred to in this article are policy documents where the two terms can be found interchangeably. The discussion here is thus more on an operational level of the concepts rather than a strict academic use (for more on the emergence of the concepts see [24,25]).

The OECD has used the concept of the BE and defined it as "transforming life science knowledge into new, sustainable, eco-efficient and competitive products” [1]. The OECD [10] has pointed towards the potentials of innovations in the transformation and more efficient use of bio-based resources. The USA has defined the concept in a similar way, although not emphasizing the sustainability aspect: "A bio-economy is one based on the use of research and innovation in the biological sciences to create economic activity and public benefit” [2]. The concept of the BE is focused on the methods of conversion of raw material into value added products. 
Figure 1. Number of citations in Scopus with "bio-based economy”, "biobased economy”, "bioeconomy" or "bio-economy" in titles, abstract or keywords.

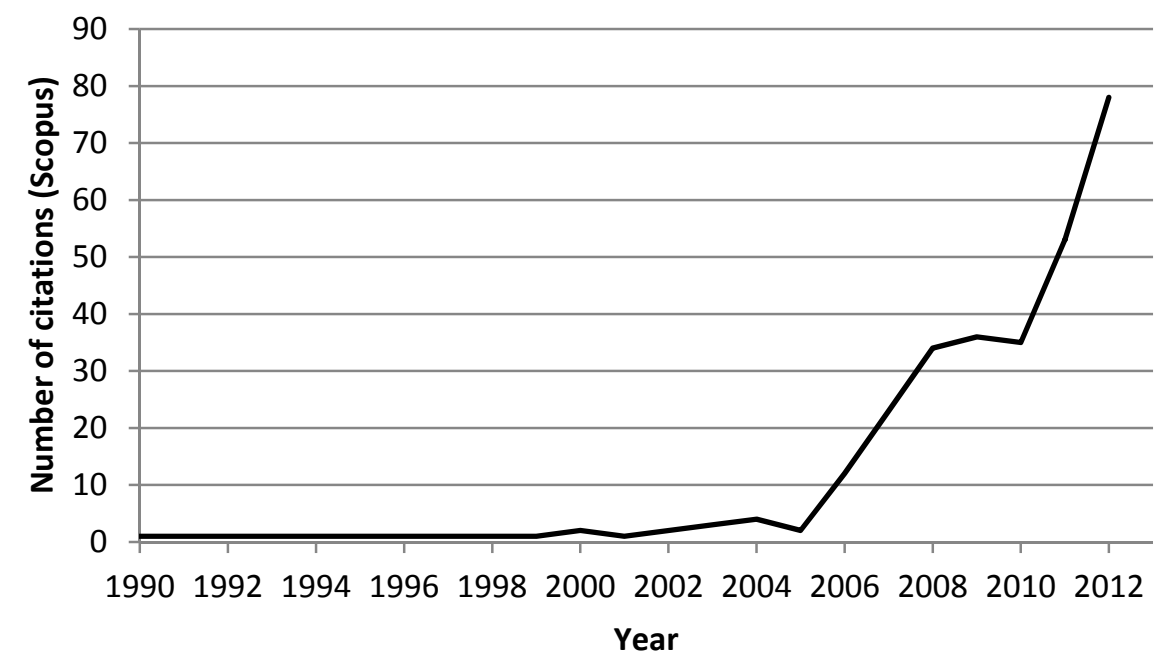

Turning towards the concept of the BBE, a slightly different meaning is emerging. An early EU definition of the BBE, in 2005, was "the sustainable, eco-efficient, transformation of renewable biological resources into food, energy and other industrial products” [25] focusing on food and energy. In more recent communications from the EU, the definition has changed to "a bio-based economy integrates the full range of natural and renewable biological resources-land and sea resources, biodiversity and biological materials (plant, animal and microbial), through to the processing and the consumption of these bio-resources” [26]. This definition of the concept focuses on the raw material rather than the conversion processes. The concept of the BBE is also used in, for example, Germany [13], Finland [15,27] and Sweden [16] with the same meaning.

This study shows that the term BE is most often used by those who define the concept as biotechnology, life science and related technologies and applications, constituting a well-defined part of the existing economy, whereas the term BBE is often used in documents where the focus is on an economy which is based on the use of biomass resources rather than fossil-based products and systems. In those few cases where a more general perspective has been applied, the concept of the bioeconomy has been used. Interestingly, when the BBE term is used, there seems to be no quantitative limit when a country has attained a BBE-it is the process rather than the goal that is the essence of the documents of the countries using that definition. However, the BE term appears to link more closely with quantification of the bioeconomy, for example, as a percentage of the total economy.

In-depth discussions about the definitions and use of the BBE concept has been published by Schmid et al. [25] and Birch and Tyfield [24]. Schmid et al. [25] discuss the definitions and use of the BBE concept and distinguish two main stakeholders: industry and the general public. Furthermore, each promotes their view and interpretations of the concept. They conclude that it is the industrial perspective that dominates in Europe and point out that a strong focus on biotechnology in the definition of the $\mathrm{BE}$ is too limiting since it does not acknowledge the role of other industrial sectors managing biological resources that contribute substantially to the BE, such as the fishery, forestry and agriculture sectors. Birch and Tyfield [24] approach the topic of the BE with a frank questioning of the popular use of the prefix "bio" to several different words and concepts. They even suggest, and are 
supported by others, that a strong engagement in the concept embeds possibilities to shape the development of it. This current article hopes to contribute to this debate.

\section{Analysis}

As the documents analyzed are of different character and serve different purposes, it is difficult to compare them in a straight forward manner. As will become clear, such a comparison can be made only by describing the main characteristics of each document. However, through the evaluation matrix (see Table 1), an overview can be presented. The matrix outlines what kind of definition is predominantly used in different strategies and policies, the type of document in terms of a political and/or technical focus, the inclusion of measureable targets and priority areas in the documents, and finally, if action plans underpin the strategies and policies.

\subsection{OECD}

“The Bioeconomy to 2030: Designing a Policy Agenda” [1] is an extensive document produced by the OECD with both a broad and deep approach to the concept of the BE and its possible development. It describes the $\mathrm{BE}$ as "a world where biotechnology contributes to a significant share of economic output” which is a definition more of the BE than the BBE type even though the OECD specifies that biotechnology must constitute a "significant" share. For the OECD, a BE constitutes three major elements: biotechnological knowledge, renewable biomass and integration across applications. The economic growth in a BE should maintain environmental sustainability, which requires decoupling of economic growth from environmental degradation. The aim of the document is to describe the situation regarding the BE in 2009, where it can be in 2015 and what it might look like in 2030.

The OECD points out that a BE will be global, and the document has a clear economic character, based on the fact that both OECD and non-OECD countries face the challenges of a growing population having consequences for the environment, social structure and the economy. The need for new business models is discussed, as well as the need for cross-sectoral collaborations and efforts. The OECD highlights the current situation that even though $75 \%$ of future economic contributions to the $\mathrm{BE}$ are likely to come from agricultural and industrial applications, over $80 \%$ of research investment from the private sector goes to health applications. The OECD therefore proposes to boost agricultural and industrial research by increased research funding from the public sector, reduced regulatory constraints and encouragement of public-private partnerships in these sectors. It also proposes the use of biotechnology to address global environmental issues by supporting international agreements to create and sustain markets for environmentally sustainable biotechnology products.

The need for a foundation for long-term development of the BE, and the need for cross-sectoral work both in terms of sectors and between governments, citizens and firms, are highlighted by the OECD. The estimation for the BE contribution to GDP in OECD countries in 2030 is $2.7 \%$, assuming a "business as usual" development of institutional factors such as regulations. The development up to 2030 is described using two fictional scenarios: one in which innovations in agriculture, health and industry are encouraged and a rapid development is seen and another, where such development is hindered by resistance from the general public. The scenarios also explore the growing competition 
between renewable fuels from "traditional” biomass, algae and electric transportation systems, which is quite progressive and not a widespread issue in documents of this type from 2009.

\section{2. $E U$}

The EU strategy presented in 2012 is entitled "Innovating for Sustainable Growth: A Bioeconomy for Europe” and it is divided into two documents: a communication [3] and a working document [11]. The former sets the scene and presents the strategy and the working plan. The latter presents the action plan in more detail and also presents some scenarios and policy interaction that arises from the strategy document. The working document specifies some of the background documents included in the preparatory work for the strategy, which include two reports compiling the results of public consultation among European stakeholders in the private sector, academia, public sector and NGOs [26,28].

This strategy for the bioeconomy is in many ways a natural consequence of the EU 2020 climate related goals, established in 2008 [29] and the EU 2020 strategy from 2010 called "A strategy for smart, sustainable and inclusive growth" [30]. Linked to these is also the resource efficiency platform [31]. All these documents related to the need of a shift from fossil-based economy clearly show the EU acknowledgement of the importance of this issue. Even though the term bioeconomy is used in the strategy, it is used in the broader sense of a bio-based economy: "The bio-economy encompasses the production of renewable biological resources and their conversion into food, feed, bio-based products and bioenergy. It includes agriculture, forestry, fisheries, food and pulp and paper production as well as parts of chemical, biotechnological and energy industries.” The strategy takes a global approach, stating the challenges regarding societal challenges (from food supply and security to an increasing population and resource efficiency) and the development of a BE. Following this setting of the scene and presenting the challenges, an action plan is presented, based upon three pillars: investments in research, innovation and skills; reinforced policy interaction and stakeholder engagement; and enhancement of markets and competitiveness in the BE.

The working document accompanying the strategy and action plan provides more details on both the background and the action plan. Although the EU definition of a BBE is an economy that relies on non-fossil resources, the working document acknowledges that there already is a BE, having a turnover of about $€ 2$ trillion and employing 22 million people (approximately $9 \%$ of the total work force). The difference from the USA is that the EU differs between the concepts "bioeconomy" and "bio-based economy" thus considering that the economy is not yet bio-based.

The working document specifies activities within areas such as social innovations, agriculture and fishery, livestock production, aquaculture, forest, biorefinery, food (waste, safety and packaging) and biotechnology. It is thus detailed and covers a broad range of sectors playing central roles in the shift to a BBE. Both the strategy and the working document stress that there are major challenges associated with a shift to a BBE, including that challenges are global and the EU must take responsibility and do a "fair share" of the work considering its advanced positions in economic terms, technology and knowledge. The issues of consumption patterns and resources being limited are addressed, which is quite unique among the documents included in this study. 


\subsection{USA}

The "National Bioeconomy Blueprint" [2] for the USA was released in 2012, and it is divided into two distinctive parts. The first describes the background and impact of the current BE in the USA and the second deals with the strategic objectives. This is a policy document that describes the actions of the government in the area of the BE earlier, today and in the future. A BE is based on the use of research and innovation in the biological sciences to create economic activity and public benefit. The driving forces behind the $\mathrm{BE}$ are economic growth, societal benefits, health and environment, as well as the USA being a leading nation in the field. Three technologies are pointed out as being the foundation for the BE: genetic engineering, DNA sequencing and automated high through-put manipulations of biomolecules. The BE is illustrated through listed "trends": health, energy, agriculture, environment and sharing. The last trend refers to the sharing of information between different sectors of society and what can be described as transdisciplinary communication.

The second part of the document deals with the strategic objectives of a BE and how different fundings and collaborations between government departments and funding agents can contribute to the development of the $\mathrm{BE}$. The strategic objectives encompass: supporting $\mathrm{R} \& \mathrm{D}$ investments for the future $\mathrm{BE}$; facilitating transition from lab to market; forming and reforming regulations that will facilitate the BE development; adapting training and aligning institutional incentives for a national BE workforce; and supporting public-private partnerships. For each objective, a detailed description of the topic follows, as well as a description of necessary actions to be taken. Examples of actions are research programs, regulatory actions, and reviewing programs in the higher education system.

The document states that the USA already has a BE and lists some of the results achieved to date. Federal departments and agencies supporting biological research, considered one of the important cornerstones in a BE, are also listed to show how strongly the BE vision is founded on a national level. The purpose of the blueprint is to lay out strategic objectives that will help to realize the full potential of the BE in the USA and to highlight positive results achieved on the way to this goal. As the focus of the strategy is biological research, the perspective is national with little outlook to the rest of the world.

\subsection{Canada}

The "Canadian Blueprint: Beyond Moose and Mountains" [12] was published in 2008 with the statement "how we can build the world's leading bio-based economy". It is not a governmental document as it is published by BioteCanada, an association representing the biotechnology sector in Canada. There is no official strategic document for the development of a BE in Canada, nor any signs of one being prepared. The document is, as the USA equivalent, a policy document describing the role of the bioeconomy in Canada in the past, present and future. The bioeconomy is defined as biotechnology and these terms are used synonymously throughout the document. The importance of the bioeconomy and biotechnology is said to be its potential to increase quality of life, being an economic pillar for Canada and a means to regain and then stay at a top international position in the field. The document emphasizes the need for immediate action and specifies goals within the selected priority areas of capital, people and operational environment. 
Success will be measured in at least three ways: the BE as percentage of GDP; growth in Canada's percentage of the world bio-based sector; and the world's adoption of Canadian biotechnology. The Canadian document is the only one of the main documents analyzed that specifies how success will be measured. Quantitative measurements of success include value of the biotechnology industry in terms of value of expenditure, number of employees, sales revenue and other parameters such as per capita increase of ideas turned into commercial products, services and/or technologies, percentage of graduates in biotechnology and related sectors and also measurable effects on the environment.

The strategy also includes sections on what the BBE means for citizens, giving examples of benefits that people will experience: better health, new materials, pesticide-free food, better environment, and increased work opportunities. Last, the document lists significant milestones in the biotech sector since 1880. The document is explanatory and directed to the general public rather than politicians or scientists. Although it is not a governmental document, it is generally referred to as an official strategy —both on Canadian and international websites.

An interesting development in Canada is that in 2011, British Columbia (BC) formed a bioeconomy committee under the direction of the Minister of Jobs, Tourism and Innovation. The role of the committee was to investigate the opportunities for the province in the emerging bioeconomy and also the possibilities for BC to speed up the growth of the BBE in the province and has, as an outcome, published a bioeconomy strategy for $\mathrm{BC}$ [32]. The committee focuses on the economic value of biological systems. Having significant forest resources, BC views the increased use of biomass for energy and material as opportunities and has also earlier taken an active role in the work to decrease the dependence on fossil resources when, in 2008, a bioenergy strategy for the province was published.

In the BC strategy, the forest sector plays an important role together with agriculture, life science and clean technology. The document is a strategic intelligence in the field of BE and identifies five key areas in which action is needed: establishment of a clear, long-term bioeconomy vision; improvement of access to fiber and feedstock; establishment of a technology development strategy; development of markets for BC bio-products; and integration of the needs of the bioeconomy into provincial initiatives. The committee also recommends the formation of a bioeconomy team to formulate and articulate the vision for the province, and points to a certain urgency in the matter in order to provide positive signals to the market and other stakeholders.

In 2013, Alberta also published a bioeconomy policy document [33], in which recommendations for building the province's bioeconomy are given. The recommendations relate to priority areas of investment described in the report. Driving forces for the development of a BE include securing Alberta's economic future, advancing world-leading resource stewardship and investing in families and communities. The document presents a broad approach to the field of $\mathrm{BE}$ and resembled the strategy of BC more than it resembles the document of BioteCanada in the sense that it does not focus on biotechnology.

Alberta is one of Canada's largest producers of agricultural products and it is also a significant producer of forest products, which constitutes favorable prerequisites for the development of a BE. Biomaterials, biochemical, and bioenergy are areas that until now have taken only marginal roles in Alberta's economy but are foreseen to grow. Ecosystem services are one of the priority areas and identified gaps regarding research and capacity are identified together with suggested actions to fill them. 


\subsection{Germany}

Germany has a bioeconomy council, established in 2009, which is an independent advisory board to the government for all matters regarding the bioeconomy. It consists of experts from academia, private sector research and from the federal government's departmental research. The role of the bioeconomy council is to contribute to enabling a leading position for Germany in a future BE and it has published a number of recommendations [13,14] for actions and the national strategy itself is based on its recommendations. The German strategy entitled "National Research Strategy Bioeconomy 2030: Our Route Towards a Biobased Economy” [34] was published in 2011, before the official EU strategy. The bioeconomy council has published support documents both before and after the publication of the strategy (see for example $[13,14]$ ) containing explanations to the strategy and recommendations for actions.

The German bioeconomy strategy is national, but with a global outlook. It is built on several pillars and covers numerous sectors, the impetus being on the field of biotechnology. One of the main objectives is that Germany become a world-renowned innovation center and that the German economy is competitive and leading in a global arena. The main topics for action are: securing global nutrition; ensuring sustainable agricultural production; producing healthy and safe foods; using renewable resources for industry; and developing bio-based energy carriers. The aforementioned fields are specified in more detail and there are examples within each field on research needs, ongoing funding, and goals and also measures on how to reach the goals. The description of each field includes specifications of which guidelines that will be followed for the implementation of the measures described.

The strategy also includes cross-sectoral activities, such as transdisciplinary research, facilitating implementation of new innovations and technologies through the actions of many parties (academia, SME and industry), exploiting international collaboration and knowledge sharing and intensifying dialog with society. In contrast to the other country policies and strategies, the German document has a clear and quite straightforward approach with outlined visions, goals and tools to reach them. The measures are quite precise and concrete. The document deals with the future from many points of view, taking into account a systems perspective. While there is a global perspective, the focus is on a national level and how Germany can benefit from the bioeconomy.

\subsection{Finland}

Currently, Finland has no official BE strategy, although one will be published for discussion and decision during 2013 by the Ministry of Employment and the Economy in cooperation with the Ministry of Agriculture and Forestry and the environmental administration in Finland. However, Finland has at least two documents [15,27] that serve as background to the soon-to-be-published official strategy. The goal envisioned for the strategy is to develop a new commercial sector and increase employment through the development of products and services relying on the use of biomass resources [35]. The term used for the presentation of the upcoming strategy is "bioeconomy", even though the interpretation of the concept clearly is in line with parties more often using the term "bio-based economy". 
As suggested, while the official strategy is not published, there are, however, a number of documents available that can be interpreted as preparations for this upcoming strategy $[15,27,36]$. These documents approach the BBE as encompassing both the use of limited resources and the processes of turning them into valuable products in a sustainable manner. The perspective is national but with a global outlook, acknowledging that Finland must do its fair share of the work since they have access to rather vast biomass resources and water in relation to its population.

The use of the expression "glocal solutions" [15] clearly shows the perspective used for the BBE in Finland. It is argued that the global and local levels need to be connected. A vision of a nearly self-sufficient society in terms of nutrients, food and energy is presented, followed by a description of what has to be achieved in order to make this vision a reality. Drivers and pathways are presented and bring up the issues of resource scarcity, mentioning particularly phosphorous. Business models and value networks are described as well as pathways leading to the vision. The Finnish documents also address the issue of consumption patterns.

\subsection{Sweden}

The Swedish strategy for a bio-based economy [16] was published by the Swedish Research Council for Environment, Agricultural Sciences and Spatial Planning in collaboration with the Swedish Energy Agency and the Swedish Innovation Agency on the assignment by the government, thus considered here as a national strategy. The purpose of the strategy was to form a basis for a research and innovation bill from the government. The strategy describes the current situation both globally and nationally, and subsequently identifies knowledge gaps and proposes key themes for further research necessary for a shift to a BBE. These themes are a replacement for fossil-based raw materials with bio-based, smarter products and smarter use of raw materials, change in consumption patterns and the prioritization and choice of measures.

The strategy discusses many aspects affected by a shift to a BBE, including new value chains, the central role of ecosystem services (both those which are easy to value in economic terms and those which are not, such as recreation and biodiversity), consumption, replenishing and recycling. In subsequent chapters, the roles of different funding bodies are discussed and cooperation between academic institutions and industry in different cross-sectorial ways and the need for coordination between research funding bodies, researchers and commerce is highlighted. Innovation incentives are discussed for both short-term and long-term investments and several initiatives for further development are proposed. The document clearly has a broad approach to the BBE and addresses numerous aspects of both the BBE itself and the ways to reach it. The perspective is national, but in a global context.

\subsection{Australia}

Biotechnology Australia and the Department of Agriculture, Fisheries and Forestry commissioned a report in 2008 entitled "Biotechnology and Australian Agriculture: Toward the Development of a Vision and Strategy for the Application of Biotechnology to Australian Agriculture” [17]. There is no official national BE strategy for Australia. Instead, the government has separate strategies for several related areas and it has not gathered them into one single document. However, the government refers 
to the document described for matters in the area of the bioeconomy and it is, for this purpose, considered an official document. The document deals with the concept of the bioeconomy as an emerging concept, not yet firmly established, of which agro-biotechnology is a key part. Therefore, the focus is on biotechnology and the use of the term aligns with the BE rather than the BBE.

The scope of the document is to inform the government on how to move forward with biotechnology in agriculture. It starts with mapping the current situation, and then identifies opportunities (such as increase in demand of renewable fuels), threats (including biosecurity) and how Australia can respond to the key drivers. The document covers research, community and industry perspectives of a market growth and proposes ways to move forward. It also includes examples of suitable actors and their respective responsibilities.

The document recognizes the emerging concept of the bioeconomy and how more and more areas of biotechnology are incorporated in this concept. The document deals with biotechnology applications in the agricultural sector and therefore emphasizes the importance of consumer trust for the technologies in question. With this in mind, four strategic imperatives are identified: a national path to market for biotechnology products and services will be needed; necessity to build consumer knowledge of biotechnology sciences and their applications (risks and benefits) and also a consumer confidence in regulation; refocus the current regulation of genetic modification from an input-based process to an output-based process to ensure consistency across emerging technologies; and Australia must be engaged in international biotechnology science and research as a part of the BE.

Interestingly, the Commonwealth Scientific and Industrial Research Organisation (CSIRO), which is the national science agency in Australia, has created a web portal on the bioeconomy, where it lists the national research flagships that deal with bioeconomy-related areas such as biosecurity, climate adaptation, sustainable agriculture and water issues. The CSIRO has also published two articles on the topic of biosecurity in a growing bioeconomy, in which the risks of using biologically modified feedstock for production of food, feed and other purposes is addressed [37,38]. This issue is closely related to the development of a BE but brought up in only a few of the strategic documents. In practice, Australia has a broad range of activities related to the development of a BBE, but they are not framed in a single strategic document.

\section{Discussion}

There is a striking variation in the types of documents analyzed. They are published between 2008 and 2012, which is a period in which the frequency of scientific articles on the topic more than doubled, as shown in Figure 1. The sources of the documents range from national agencies to purely industrial stakeholders, which is reflected in the main focus of the documents and the approaches taken to the topic of the bioeconomy. However, there are three major cross-cutting issues that are present in both the BBE and BE strategies and policies. These issues include: (i) the balance between sustainability and economic aspirations; (ii) the limited attention to measuring progress; and (iii) the challenge of a limited supply of resources. The countries and regions analyzed in this article show that there are quite different levels of development and understanding of the BBE and BE. However, a general point that demands attention based on these combined issues is that there are serious gaps and/or assumptions in the strategies and policies for expanding the bioeconomy. 


\subsection{Promoting Sustainability}

The BE and BBE are concepts concerned with the productive (economic) uses of biomass and biomass conversions. A striking feature is how seldom the sustainability aspect of the use of biomass is mentioned as a driving force. It is especially true for the documents published by industrial stakeholders and for the documents of a purely political nature. Furthermore, only a few of the documents acknowledge the global responsibility to contribute to, for example, climate mitigation, such as Finland, Sweden and Germany. The main driving force is in many cases growing the economy and reaching or retaining a world leading position in the field.

This might very well be the correct way to actually get the desired development since few companies will invest in new technologies and/or equipment unless the economy is favorable compared to traditional technologies based on non-sustainable raw materials and energy. However, as new technologies are often associated with high initial costs, a common strategy for nations is to give support to contribute to goals and ambitions set by governments. It is not only the high costs of the new technologies that hamper the transition to a bio-based economy, but also the competition from corresponding fossil-based technologies. The situation often renders new technologies economically unviable or associated with risks so high that investments in new technologies are avoided. From this perspective, it is likely that the policies have the purpose to indicate for industrial actors what the ambitions are in governments. The USA document [2] is an example where the administration stipulates their ambitions and visions of the sector in the future.

The BE and BBE strategies and policies are focusing on the opportunities based on utilizing bio-based resources. The consequences that this will have on the dependency and utilization of other resources are often not discussed. To illustrate this problem, the case of biofuels can be given where the opportunity of biofuels to replace fossil resources is linked to changes in water use, new patterns in land use, and also the use of chemical fertilizers and pesticides. It is probable that the BE or BBE is not a panacea, but should be seen as one piece in the puzzle of initiatives to tackle the challenges faced by the global community to take steps in a more sustainable direction.

\subsection{Measuring Progress}

A means to measure progress in attaining the ambitions and targets set in the policies and strategies in the bioeconomy is lacking. Only in the Canadian strategy is there a system that clearly spells out a way to measure progress that goes beyond economic values and shares of GDP included. And even the Canadian measures are limited. The difficulty of measuring success can be a consequence of the lack of a clear definition of the BE or BBE concept and also that concrete goals, which allow for follow-ups and measurements, are not specified in most documents. It is fundamental to the success and sustainability of the bioeconomy that measurements for progress are defined and applied.

One of the challenges to realizing the potentials seen in the BE and BBE policies and strategies is the need for large investments in infrastructure and new technology in the processing industry. The policies studied are, however, documents setting the direction to policy designers and stakeholders to act on. Support structures and learning curves making investments more conducive are foreseen, but a main question is whether this will be enough to make these major changes. The EU document [3] 
provides an example, as it is part of a whole package of policies and communications from the EU aiming towards, among other things, resource efficiency, reducing climate impacts, and supporting innovation. These shifts are paradigmatical and cannot be realized unless changes take place in society and the economy.

\subsection{Supplying Resources}

It is widely acknowledged that many resources will in the future be limited [39-41]. In addition to peak oil, peak phosphorus is approaching [42-44] and the debate on whether there is enough biomass for all applications and industries [45] shows that there is a well-founded fear that we are facing a future where many resources will be scarce. In 2010, the World Business Council published a vision for 2050 [46] with the main vision being "9 billion people living well within the boundaries of one planet". The inclusion of the last part of the vision "within the boundaries of one planet" shows that this is a major part of the challenge. These issues are surprisingly absent in most of the documents on the $\mathrm{BE}$ and $\mathrm{BBE}$.

Interestingly, the issue of resource scarcity is addressed more in strategies and policies for a BBE than in the documents for a $\mathrm{BE}$, which is in line with what is generally encompassed in the two concepts. The BE documents generally focus on life sciences and biotechnology, where resources and feedstocks are not relevant parameters and neither is the scarcity of such. In a BBE, the issues of feedstock conversion to energy, food, feed and materials are the basis of the economy and therefore, the availability (and scarcity) of resources are highly relevant and thus more often addressed in the strategies. The Australian document is an example where the focus is on developing biotechnology and economic opportunities with limited analysis of the availability of resources and potential conflicts between industries over inputs, such as water.

\section{Conclusions}

The aim of this article was to give a comparative analysis of a sample of national strategies and policies on the BE and BBE. The difference between the BE and BBE has been discussed and different operationalizations of these concepts has been presented. As mentioned, the BE term is predominantly used when referring to the biotechnological and life science part of an existing economy, whereas the term BBE is used for describing an economy which is predominantly based on biomass for food, feed, energy and other purposes, rather than fossil-based resources. In short, the "bio-economy" is often understood as a sector, whereas the "bio-based economy" refers to a transformation of the economy as a whole. This difference is an interpretation identified in this research. The two terms can also be used interchangeably, and the BE can be considered a part of the BBE, constituting the process part and not encompassing the resource to the same extent as the BBE. Whether this difference has any implications for a global approach to the challenge of shifting from a fossil-based economy to a bio-based economy is not obvious, but it is clear from the work performed here that the purposes with a strategy or vision for a $\mathrm{BE}$ or BBE correlates with the term used.

In a sense, the strategies and policies for a BE and BBE must be seen in the context of a strong push for reducing the dependency on fossil resources. Many of the biotechnology processes considered in the realm of the BE and BBE includes replacing fossil resources with products based on bio-based 
materials. At the same time the actors are, most probably, well aware that the amount of biomass available will not be enough to replace all fossil resources presently used globally-but the BE and BBE brings a promise of both continuing economic growth and a transition away from fossil fuels. Another feature is that the countries and regions included in this study all have a strong position or interest in life science, bioenergy and/or bio-based products and industries, such as forestry or agriculture. Again, the challenges in the context of climate change and the need to replace fossil resources sets the light on the potentials of venturing into and supporting a development of the BBE or BE.

At the same time the BE and BBE concepts are not well defined. In some cases, it is a more political approach and, in others, a more scientific approach has been applied in the presentation of what is meant by these concepts. At present, the BBE and BE is often used as a buzzword or technical fix for the challenge of taking steps in the transition away from fossil fuels. In the years to come, the ambitions set in the strategies and policies for the bioeconomy will be tested. We foresee a need for considerable support in the forms of policies and/or financial instruments introduced for making the required investments economically feasible and manageable by industrial stakeholders as a major challenge. In addition to this, we argue that there is a need to integrate a stronger environmental and sustainability component in the BE and BBE approaches, which should be closely connected with supply and production of bioresources, as well as consumption patterns.

\section{Acknowledgments}

This article is the result of a project funded by the Swedish Knowledge Centre for Renewable Transportation Fuels (f3 Centre). The aim of the $\mathrm{f} 3$ Centre it is to contribute to the development of sustainable fossil-free fuels for transportation in Sweden and is financed by the Swedish Energy Agency, the Region Västra Götaland, and the partners of the f3 Centre, including universities, research institutes, and industry.

\section{Conflict of Interest}

The authors declare no conflict of interest.

\section{References}

1. Organisation for Economic Co-operation and Development (OECD). The Bioeconomy to 2030: Designing a Policy Agenda; Organisation for Economic Co-operation and Development (OECD): Paris, France, 2009; p. 326.

2. White House. National Bioeconomy Blueprint; White House: Washington, DC, USA, 2012; p. 48.

3. European Commission. Innovating for Sustainable Growth: A Bioeconomy for Europe; COM(2012) 60 final; European Commission: Brussels, Belgium, 2012; p. 9.

4. BIO2020. Summary State Coordination Program for the Development of Biotechnology in the Russian Federation until 2020 "BIO 2020”; State Coordination Program for the Development of Biotechnology in the Russian Federation until 2020 (BIO 2020): Moscow, Russia, 2012; p. 22.

5. Fulton, M. 12th Five Year Plan-Chinese Leadership Towards a Low Carbon Economy; DB Climate Change Advisors, Deutsche Bank Group: Frankfurt am Main, Germany, 2011; p. 16. 
6. Boterman, B. Bio-Economie in China; Rathenau Instituut and TWA Netwerk Kingdom of the Netherlands: The Hague, The Netherlands, 2011; p. 42.

7. Biotechcorp Malyasian Biotechnology Corporation. Available online: http://www.biotechcorp.com.my/ (accessed on 4 April 2013),

8. AIM. National Biomass Strategy 2020: New wealth creation for Malaysia's palm oil industry; Agensi Inovasi Malaysia: Kuala Lumpur, Malaysia, 2011; p. 32.

9. Presidência da República Decreto no 6041, Anexo Política de Desenvolvimento da Biotecnologia; DECRETO No 6.041, DE 8 DE FEVEREIRO DE 2007; Presidência da República, Brasil: Brasilia, Brasil, 2007; p. 35.

10. Organisation for Economic Co-operation and Development (OECD). The Bioeconomy to 2030. Designing a Policy Agenda; Organisation for Economic Co-operation and Development (OECD): Paris, France, 2006; p. 12.

11. European Commission. Commission Staff Working Document accompanying the document Innovating for Sustainable Growth: A Bioeconomy for Europe; European Commission: Brussels, Belgium, 2012; p. 51.

12. BioteCanada. The Canadian Blueprint: Beyond Moose \& Mountains. How we can build the world's leading bio-based economy; BioteCanada: Ottawa, Canada, 2009; p. 20.

13. BÖR. Bio-Economy Innovation. Research and Technological Development to Ensure Food Security, the Sustainable Use of Resources and Competitiveness; BioÖkonomieRat: Berlin, Germany, 2011; p. 60.

14. BÖR. Internationalisation of Bio-Economy Research in Germany. First Recommendations by the BioEconomyCouncil; BioÖkonomieRat: Berlin, Germany, 2012; p. 60.

15. Luoma, P.; Vanhanen, J.; Tommila, P. Distributed Bio-Based Economy-Driving Sustainable Growth; Finnish Innovation Fund (SITRA): Helsinki, Finland, 2011; p. 24.

16. FORMAS. Swedish Research and Innovation Strategy for a Bio-based Economy; R3:2012; Swedish Research Council for Environment, Agricultural Sciences and Spatial Planning (FORMAS): Stockholm, Sweden, 2012; p. 36.

17. ACIL Tasman. Biotechnology and Australian Agriculture. Towards the development of a vision and strategy for the application of biotechnology to Australian Agriculture; ACIL Tasman: Melbourne, Australia, 2008; p. 94.

18. Kircher, M. The transition to a bio-economy: National perspectives. Biofuel. Bioprod. Bior. 2012, 6, 240-245.

19. Kircher, M. The transition to a bio-economy: emerging from the oil age. Biofuel. Bioprod. Bior. 2012, 6, 396-375.

20. Pan, Y.; Birdsey, R.A.; Fang, J.; Houghton, R.; Kauppi, P.E.; Kurz, W.A.; Phillips, O.L.; Shvidenko, A.; Lewis, S.L.; Canadell, J.G.; et al. A Large and Persistent Carbon Sink in the World's Forests. Science 2011, 333, 988-993.

21. Mata, T.M.; Martins, A.A.; Caetano, N.S. Microalgae for biodiesel production and other applications: A review. Renew. Sust. Energ. Rev. 2010, 14, 217-232.

22. Wijffels, R.H.; Barbosa, M.J. An outlook on microalgal biofuels. Science 2010, 329, 796-799.

23. Scopus Scopus-Document search. Available online: http://www.scopus.com (accessed on 25 March 2013). 
24. Birch, K.; Tyfield, D. Theorizing the Bioeconomy: Biovalue, Biocapital, Bioeconomics or What? Sci. Technol. Hum. Values 2013, 38, 299-327.

25. Schmid, O.; Padel, S.; Levidow, L. The Bio-Economy Concept and Knowledge Base in a Public Goods and Farmer Perspective. Bio-Based Appl. Econ. 2012, 1, 47-63.

26. European Commission. Bio-based economy for Europe: state of play and future potential-Part 1. Report on the European Commission's Public on-line consultation; European Commission: Brussels, Belgium, 2011; p. 92.

27. Gustafsson, M.; Stoor, R.; Tsvetkova, A. Sustainable Bio-economy: Potential, Challenges and Opportunities in Finland; SITRA studies 51; PBI Research Institute: Helsinki, Finland, 2011; p. 64.

28. European Commission. Bio-based economy for Europe: state of play and future potential-Part 2. Summary of the position papers received in response of the European Commission's Public online consultation; European Commission: Brussels, Belgium, 2011; p. 30.

29. European Commission. 2020 by 2020 Europe's climate change opportunity; COM2008 30 final; Commission of the European Communities: Brussels, Belgium, 2008; p. 12.

30. European Commission. Europe 2020 A Strategy for smart, sustainable and inclusive growth; COM(2010)2020; European Commission: Brussels, Belgium, 2010; p. 37.

31. European Commission. A resource-efficient Europe-Flagship initiative under the Europe 2020 Strategy; COM(2011)21; European Commission: Brussels, Belgium, 2010; p. 16.

32. Yap, J.; Simpson, B.; Cantelon, R.; Rustad, J.; Foster, E. BC Bio-Economy; Bio-Economy Committee: Brittish Colombia, Canada, 2011; p. 37.

33. AI Bio. Recommendations to Build Alberta's Bioeconomy; Alberta Innovates Bio Solutions (AI Bio): Edmonton, Canada, 2013; p. 34.

34. BMBF. National Research Strategy BioEconomy 2030. Our Route towards a biobased economy. Bundesministerium für Bildung und Forschung (BMBF): Berlin, Germany, 2011; p. 56.

35. Biotalous Biotalous. Available online: http://www.biotalous.fi/ (accessed on 25 March 2013),

36. SITRA. Natural Resources-An Opportunity for Change; the Finnish Innovation Fund (SITRA): Helsinki, Finland, 2009; p. 56.

37. Sheppard, A.W.; Raghu, S.; Begley, C.; Genovesi, P.; de Barro, P.; Tasker, A.; Roberts, B. Biosecurity as an integral part of the new bioeconomy: A path to a more sustainable future. Curr. Opin. Environ. Sustain. 2011, 3, 105-111.

38. Sheppard, A.W.; Raghu, S.; Begley, C.; Richardson, D.M. Biosecurity in the new bioeconomy. Curr. Opin. Environ. Sustain. 2011, 3, 1-3.

39. Aleklett, K.; Höök, M.; Jakobsson, K.; Lardelli, M.; Snowden, S.; Söderbergh, B. The Peak of the Oil Age-Analyzing the world oil production Reference Scenario in World Energy Outlook 2008. Energy Policy 2010, 38, 1398-1414.

40. Hoff, H. Understanding the Nexus. Background Paper for the Bonn 2011 Conference: The Water, Energy and Food Security Nexus; Stockholm Environment Institute (SEI): Stockholm, Sweden, 2011; p. 52.

41. WWF. Living Planet Report 2012, Biodiversity, biocapacity and better choices; WWF International: Gland, Switzerland, 2012; p. 164. 
42. Schröder, J.J.; Cordell, D.; Smit, A.L.; Rosemarin, A. Sustainable Use of Phosphorus; 357; Plant Research International and Stockholm Environment Institute (SEI): Wagenigen, The Netherlands, 2010; p.140.

43. UNEP UNEP Yearbook: Emerging Issues in our Global Environment 2011; United Nations Environment Programme (UNEP): Nairobi, Kenya, 2011; p. 92.

44. Cordell, D.; Drangert, J.-O.; White, S. The story of phosphorus: Global food security and food for thought. Global Environmen. Change 2009, 19, 292-305.

45. Chum, H.; Faaij, A.; Moreira, J.; Berndes, G.; Dhamija, P.; Dong, H.; Gabrielle, B.; Goss Eng, A.; Lucht, W.; Mapako, M.; et al. In IPCC Special Report on Renewable Energy Sources and Climate Change Mitigation; Edenhofer, O., Pichs-Madruga, R., Sokona, Y., Seyboth, K., Matschoss, P., Kadner, S., Zwickel, T., Eickemeier, P., Hansen, G., Schlömer, S., von Stechow, C., Eds.; Cambridge University Press: Cambridge, UK and New York, NY, USA, 2011.

46. WBCSD. Vision 2050; World Business Council for Sustainable Development (WBCSD): Geneva, Switzerland, 2010; p. 80.

(C) 2013 by the authors; licensee MDPI, Basel, Switzerland. This article is an open access article distributed under the terms and conditions of the Creative Commons Attribution license (http://creativecommons.org/licenses/by/3.0/). 